Muschalla, B. (2019). Psychological capacity limitations according to Mini-ICF-APP are differently related with sick leave in patients from different professional fields. Journal of Psychosomatic Research, in press.

Psychological capacity limitations according to Mini-ICF-APP are differently related with sick leave in patients from different professional fields

Short running head: work disability in different professions

4171 words manuscript text, 3 tables, 40 references

Beate Muschalla

Technische Universität Braunschweig, Psychotherapy and Diagnostics, Germany

Original article for publication in Journal of Psychosomatic Research

Conflicts of interest: The author declares that she has no conflicts of interest.

Acknowledgment: The manuscript underwent English proofread by Kelly GmbH.

Funding: This research has been funded by a research grant from the Federal German Pension Agency: 8011-106-31/31.51.6

Address for correspondence: Prof. Dr. Beate Muschalla, Technische Universität Braunschweig, Psychotherapy and Diagnostics, Humboldtstraße 33, 38106

Braunschweig, Email: beate.muschalla@gmx.de, ORCID-ID: 0000-0001-5285-6618 


\title{
Psychological capacity limitations according to Mini-ICF-APP are differently related with sick leave in patients from different professional fields
}

\begin{abstract}
Objective: Up to $29 \%$ of the working population suffer from (chronic) mental disorders and work disability. As different professions pose different psychological capacity demands, one core aspect for describing work disability is psychological capacity limitations. The distribution of capacity limitations in patients with chronic mental disorders (CMD) from different professional fields is unknown, as well as their relation with sick leave.

Objective: Are there different work ability limitations in CMD patients working in different professions?
\end{abstract}

Methods: 263 CMD patients from different professions were investigated cross-sectionally in a thorough medical and psychological assessment by a trained psychosomatic study physician. Besides CMD diagnostic (MINI) and subjective work ability limitations (IMET), an observer rating on capacity limitations was conducted with Mini-ICF-APP.

Results: No relevant differences in perceived work ability limitations were found between the professions. Differences of capacity limitations were better explained by psychopathology than by profession. But capacity limitations were differently related with sick leave in different professions and there are differences in sick leave duration.

Conclusions: The variance of capacity limitations was explained by psychopathology. The variance of sick leave duration was explained by profession. Similar capacity limitations are associated differently with sick leave in different professions. Different professional fields may have different tolerances towards the same capacity limitations. Therefore, similar capacity limitations are more or less strongly associated with sick leave in different professions. 


\section{Introduction}

Mental disorders occur in about one-third of the general population [1]. Accordingly, 14$29 \%$ of the working population [2,3] suffer from mental disorder (e.g. anxiety, depression) and related psychosocial capacity limitations. These are often associated with work disability and sick leave. Mental disorders have been found in all professions, with specific risks in social service professions $[3,4]$. However, mental health symptoms themselves are not explanative for work (dis)ability [5,6]. Thus, another level of diagnostic must be considered in work ability diagnostics, namely the level of capacities [7].

The theoretical background for understanding the concept of work (dis)ability is the interaction of persons' capacities and work demands. This has been expressed in the person-jobfit model $[8,9]$ and the current international biopsychosocial health model (International Classification of Functioning, Disability and Health ICF [10]). From both models, one may derive a relational definition of work (dis)ability: work (dis)ability is the result of capacity limitations that conflict with respective work demands.

(Psychological) capacity limitations are limitations in terms of carrying out certain (psychologically) relevant activities [10-13]. In the context of CMD, capacity limitations are illness-related. For example, a patient with a social phobia suffers from the symptom of paniclike anxiety when others regard him. The patient subsequently avoids contacts with others, reflecting a limitation in the capacity of contacts to others. Capacity limitations are illnessrelated but not illness-specific: a patient with another CMD, e.g. an obsessive compulsive disorder, can also be impaired in the capacity contacts with others, being cognitively bound with obsessive compulsive thoughts and unable to engage in small talk with new colleagues. 
Psychological capacity limitations have been investigated in the clinical context and evaluated internationally. An established observer rating for describing capacity limitations is the Mini-ICF-APP [14-18]. Thirteen capacity dimensions have been conceptualized and evaluated (see methods section [14,17]). Since mental disorders are chronic by their nature, i.e. affecting the person life-long (e.g. generalized anxiety disorder, personality disorder) or in recurrent episodes (e.g. depression), capacity limitations affect social and work participation over one's life time [18]. The life domain in which capacity limitations most often lead to problems is the workplace [20]. This is due to the fact that workplaces - more than other life domains - pose defined capacity demands and if these cannot be fulfilled, problems occur. For example, an agoraphobic person who is afraid of being in foreign places (=mental health problem) cannot drive long distances in a car (=capacity disorder in mobility) and thus is unable to fulfill a job as a field worker (=work disability) because the job requires being mobile in town and on the road.

Different capacities are needed to a different degree in different professional fields. For instance, a physical/craftsman job implies demands for physical capacities, whereas service jobs imply demands for contacts with others, i.e. working with clients. A manager/leading position implies demands for proactivity, endurance, the capacity to judge and decide. Jobs in education imply demands for team work and assertiveness (e.g. teachers working with groups and classes).

\section{Relevance of capacity limitations for work ability and occupational health}

Empirically, self-assessed work ability is an important predictor for future real work ability or sick leave, whereby perceived work ability limitations are often associated with sick leave in the future $[21,22]$. In social-medicine practice, in addition to the person's subjective 
work ability perception and the work demands, clinicians must integrate the observable capacity limitations in their judgment on work ability [11,12,23].

At present, it is unknown which psychological capacity limitations become relevant to which degree in different professional settings.

Knowing and describing the type and degree of capacity limitations is not only relevant for sick leave certification and treatment $[11,12,23]$, but also in occupational health services e.g. when workplace adjustment is questioned - or in work health prevention for employees with mental disorders. Knowing about the type of capacity disorder in a person can help to initiate specific interventions for him/her and keep the person at work. Thereby, it is important to know about the capacity level and capacity disorder - i.e. what a person can(not) do at work - even more than the diagnosis/symptoms of the mental disorder itself $[5,6]$. Knowing about the distribution and degrees of capacity limitations in different professions can be useful for general demand planning, e.g. for interventions in occupational health prevention, occupational reintegration and work adjustment. We conducted an explorative study among persons of employed age and from various professional fields who suffered from diverse chronic mental disorders (CMD).

The evidence on the distribution of type and degree of capacity limitations in CMD patients from different professional fields is currently scarce. Accordingly, this study helps to fill this gap with empirical data.

\section{Objectives}


This study explores capacity limitations according to Mini-ICF-APP [14,17] in CMD patients from different professions. The question is whether and which psychological capacity limitations hold specific relevance in different professional fields. Accordingly, the research questions are:

1. Do CMD patients from different professional groups differ in their subjective work ability limitations and their sick leave duration in the past twelve months?

2. Do CMD patients from different professional groups have different degrees of limitations in specific capacities according to Mini-ICF-APP?

3. In what way are capacity limitations related to sick leave duration in different professional groups?

\section{Method}

\section{Study design}

In order to investigate a prototypically-representative sample of patients with CMDs, patients from general practitioner offices were recruited. In 40 general practice offices, a random sample of patients in the waiting room were contacted by study psychologists and asked to fill in a screening questionnaire on their socio-demographic and medical status, whether they suffered from mental disorders as well as their present mental health overall status (WHO-5 [24]; IMET [25]). The screening included questions concerning the chronicity of the mental health problem (whether the person was suffering from the symptoms for at least 6 months or longer), as well as standardized self-rating questionnaires (see [26] for the full description of this assessment). Persons who were aged 18 to 60 and suffered from chronic mental disorders with participation problems were invited to participate in a thorough medical assessment. These assessments lasted 
90-120 minutes each. They were all conducted by the same psychosomatic study physician trained in rehabilitation medicine and diagnostic of capacity limitations. Besides a structured diagnostic of the mental health problem (MINI [27]), the study physician gave an observer rating on capacity limitations with the Mini-ICF-APP [14,17]. Additionally, participants were asked to reveal their cumulated sick leave duration in the past twelve months. The study physician's observer rating on the Mini-ICF-APP was based on information gathered from the participants in the interview and from the medical assessment. This is how social-medicine decisions and descriptions need to be conducted in practice. Therefore, this diagnostic is both objective and of high ecological validity and standard [11,12].

\section{Instruments}

Capacity limitations assessed with Mini-ICF-APP. The Mini-ICF-APP [14,17] is an observer rating instrument that is internationally evaluated $[15,16,19]$, internationally recognized [13] and established in social medicine $[11,12]$ to measure capacity limitations in the context of mental disorders. It offers a selection of capacity dimensions derived from the ICF [13]. The Mini-ICF-APP capacity limitations rating is observer rated and the usual time frame is the last two weeks. Thirteen domains of capacity are assessed: (1) adherence to regulations, (2) planning and structuring tasks, (3) flexibility, (4) applying expertise, (5) capacity to judge and decide, (6) endurance, (7) assertiveness, (8) contacts with others, (9) teamwork and group interaction capacity (10) dyadic relationships, (11) proactivity, (12) self-care, and (13) mobility. Each dimension is rated on a five-point Likert scale: $0=$ no limitations, $1=$ mild limitations without problems in the environmental context, 2 = moderate limitations causing problems in the environment, 3 = severe limitations causing problems and the necessity for assistance, and $4=$ 
total limitations and exemption from all specific role duties in the context of reference. Anchor definitions for each item are provided in the rating manual [14]. The rating uses all available information including the participant's self-report, case record and observation from the interview situation. Inter-rater reliability varies from $r=.70$ (untrained raters) to $r=.90$ (trained raters, [14]). The Mini-ICF-APP has been validated with the Groningen Social Disability Interview [28]. The Mini-ICF-APP rating in this present study was conducted with reference to the present life context of the participant. This general life context includes general capacity demands for living on one's own and applying for or working in a job on the general labor market. The "general life and general labor market context" thus gives a comparable standard environment for all participants. The study physician wrote medical case reports for each participant, which were regularly supervised by a senior socio-medical specialist.

Profession, mental disorders, subjective work ability limitations. Participants were asked to give information on their cumulated sick leave duration in the past twelve months in weeks, as well as their current profession. A priori constructed categories for occupational groups were chosen to represent divergent capacity demands, e.g. physical work/craftsmen implies demands for physical capacities, services implies demands for contacts with others (working with clients), manager/leading position implies demands for proactivity, endurance, capacity to judge and decide, as well as education implies demands for team work and assertiveness (e.g. working with groups and classes). They were also explored in terms of mental disorders according to DSM criteria by means of the established Mini International Neuropsychiatric (MINI) interview [27], which covers a broad range of CMDs (anxiety, depression, adjustment, addiction, personality disorder). Moreover, the evaluated work-anxiety interview was added for assessing workplace phobia [29]. Workplace phobia is a specific 
syndrome that is narrowly related with sick leave due to the work-directed avoidance behavior. Global subjective work ability limitations were assessed with the Index for Measuring Restrictions in Participation (IMET) [25,20], a short ICF-based self-rating asking for selfperceived illness-related participation limitations in different daily activities. The IMET includes an item for a global rating of limitations in "work and profession", which was used as a measure for subjective work ability limitations in the present study. The limitation degree is rated by the participant on a scale from $0=$ no limitations to $10=$ complete limitation.

\section{Statistical analysis}

Data were analyzed with SPSS. Descriptive statistics as well as group comparisons by analysis of variance (MANCOVA, with Bonferroni correction) were calculated. Due to the unequal distribution of two diagnosis (generalized anxiety and depression, see participants section) across the professional groups, they were considered as covariates in the analysis of variance and partial correlations (Table 2-4).

\section{Results}

\section{Participants' characteristics}

Overall, 559 out of 1,451 persons (aged 18-60) in the waiting rooms fulfilled the criteria of chronic mental disorder and participation problems in the screening questionnaire. 307 of them agreed to participate in the medical assessment. Patients who did not want to participate named different reasons: most often they were not interested (50\%) or said that they generally refused participation in studies $(17 \%)$, had other health complaints $(8 \%)$, had no time $(6 \%)$ or 
cited other reasons. 263 of the 307 participants could be included in the final analysis with full data. $65.5 \%$ currently had a workplace, and $27.7 \%$ were presently on sick leave. $19.7 \%$ had applied for an inpatient rehabilitation intervention, and $8.6 \%$ had applied for a disability pension on time. $71.1 \%$ of participants were females. Mental disorders were distributed similarly among the different professions, except generalized anxiety, which occurred more often in office workers, as well as depression, which was present most often in craftsmen (Table 1). Participants fulfilled on average $2.32(S D=1.79)$ diagnostic categories of a mental disorder according to MINI [27].

Two diagnosis were unequally distributed in the different professional groups: there was a higher proportion of generalized anxiety in office professions, and a higher proportion of depression in craftsmen. Specific capacity limitations in these groups occurred as follows: persons with generalized anxiety $(n=26)$ have higher limitations in flexibility $(M=1.42, S D=$ 1.02 vs. $M=0.93, S D=0.97, p=.02)$, decision-making and judgment $(M=1.54, S D=1.10$ vs. $M=0.97, S D=0.89, p=<.01)$, endurance $(M=1.42, S D=1.21$ vs. $M=0.95, S D=0.99, p=$ $.02)$ and proactivity $(M=1.54, S D=0.90$ vs. $M=1.16, S D=0.86, p=.03)$ compared with persons without generalized anxiety $(n=237)$. Persons with depression $(n=143)$ were significantly more strongly impaired than persons without depression $(n=164)$ in all capacity dimensions.

[please insert table 1 about here]

\section{Sick leave durations and subjective work ability limitations}


Besides craftsmen, persons from health services and education professions reported the longest sick leave durations in the past twelve months (Table 2), while persons in management or leading position had the shortest sick leave duration. The office workers had significantly shorter sick leave durations compared with craftsmen or health services.

The different professions give similar ratings concerning their perceived overall work ability limitations (IMET, Table 2). The only exception was that physical workers reported significantly higher work ability limitations than persons from high-qualified and management professions.

The correlation between sick leave duration in the past twelve months and perceived overall work ability limitations (IMET) was moderate $\left(r=.33^{* *}\right.$, Table 4$)$. However, the narrowness of the correlation varied in the different professions: among persons from education, physical work or services, a longer duration of sick leave was associated with higher subjective work ability limitations, whereas in management or health services or office work, sick leave duration and subjective work ability limitations were not significantly correlated.

[please insert table 2 about here]

\section{Capacity limitations in different professions}

Persons involved in office work had the highest limitations degrees in five out of thirteen capacity dimensions: flexibility, capacity to judge and decide, endurance, contacts and proactivity (Table 3). However, a certain amount of variance in different professional groups' capacity limitations can be explained by depression and generalized anxiety rather than by the 
professional group: by considering generalized anxiety and depression as covariates, no significant differences of capacity limitations remain between the professional groups.

[please insert table 3 about here]

\section{Capacity limitations and sick leave durations}

The relationship pattern between capacity limitations and sick leave duration was different in the different professions (Table 4): among physical workers, capacity limitations in self-care and endurance were narrowly associated with longer sick leave. In health professions, capacity limitations in endurance, applying expertise and flexibility were associated with longer sick leave. Among education professions, capacity limitations to judge and decide were associated with longer sick leave. Among service professions, capacity limitations in contacts to others and group interaction were relevant, while among managers capacity limitations in dyadic interaction were associated with longer sick leave.

[please insert table 4 about here]

\section{Discussion}

In this study, sick leave and subjective work ability limitations were not high but moderately correlated. Research shows that past history of sick leave, poor general health perception and a lower education level are predictive of sickness absence. However, no or inconsistent predictive effects were reported for activity limitations at work as well as environmental and work factors [21]. A higher work ability score was partly found to be 
positively related with return to work [30,31], although there were also findings with no effect [32]. The sample investigated here comprises patients from a general care setting. Accordingly, sick leave durations in the past twelve months may also be due to somatic illnesses in some cases, which we cannot control for given that we did not have data on the reasons for each instance of sick leave.

On the one hand, there were no relevant differences between the professions in subjective work ability limitations. Patients from different professional fields have similar degrees of capacity limitations. On the other hand, there are differences between the professions in terms of sick leave duration and differences concerning capacity limitations' relation patterns with sick leave. This is due to the different nature of the concepts: the different levels of operationalization, i.e. subjective work ability limitations (IMET), sick leave duration and observed capacity limitations (Mini-ICF-APP) target different aspects of disability. This becomes obvious in the different results from these measures, whereby degrees of capacity limitations (Mini-ICF-APP) were similar in all professions, although there were differences in (relatedness with) sick leave duration and subjective work ability limitations (IMET).

- The cumulated sick leave duration may be an indicator for the overall chronic illnessrelated physical and psychological limitations.

- Unlike sick leave duration, the subjective work ability limitation (IMET) represents a snapshot of the patient's present work ability perception, which can be partly independent from more complex health problems, and partly independent from the cumulated sick leave duration.

- Capacity limitations (Mini-ICF-APP) have been rated by a trained clinical expert, according to definitions and rating rules of thirteen specific capacity dimensions. In this 
study, capacity limitations have been assessed with reference to the general life context. Capacity limitations are distributed with similar degrees in the professions, although they are differently related with sick leave. This leads to the assumption that different capacities may be important in different work domains: for example, in health care flexibility and endurance limitations may be a more serious problem for work ability, whereas in service professions interactional capacities may be more important, and interactional limitations may thus be more easily associated with sick leave.

The descriptive finding that persons in health and education professions had relatively long sick leave durations (11-12 weeks) is similar to population data in which employees in welfare services, education and social services had an elevated risk of mental disorder sick leave [33].

The finding that persons with office work had absolutely highest capacity limitations in five Mini-ICF-APP capacity dimensions but they were not longer on sick leave than other professions leads to the hypothesis that the office work environment may tolerate limitations more than other jobs that have absolutely higher sick leave durations, e.g. health care or education. In health care and education, the professionals are strongly exposed to thirds (i.e. patients, clients, students) every working day, whereby the instability of capacities may be less tolerated and work ability may be more strongly impaired when employees have deficits in capacities.

Another important point is that there are comparably more persons with generalized anxiety among office professions (19.4\% compared with 3.4-9.3\% in the other professions). The main characteristic of generalized anxiety is worrying and the impossibility to cope with 
uncertainty [34]. For these persons, being on sick leave means uncertainty about what happens at work. This cannot be tolerated by many persons with worrying, and thus they are rarely on sick leave. It might be the case that some persons with generalized anxiety (worrying) go to work even if they are impaired.

Persons from physical work and craftsmen professions have a higher proportion of depression, longest sick leave durations but similar capacity limitation levels compared with other occupations. This fits what is known from epidemiology, i.e. that elementary professions are related with a stronger symptom load than other professions [35]. One possible explanation for the longer sick leave duration in physical work is that sick leave must not only be due to psychological capacity limitations (which was on average in this investigation, i.e. comparable with the other professions) but may occur due to a wide range of physical health problems that we could not assess in this investigation. By nature, physical work professions may be associated with limitations of physical capacities, more than the other professions. These physical limitations also affect sick leave duration. Physical workers had a higher rate of alcohol addiction, which fits to known empirical evidence [36], and may also impact on work absence.

In this sample, there were no managers with personality disorders. In contrast, empirical literature shows that certain "dark side personality traits" may occur in leading persons [37]. It may be that interactional capacities which come along with certain personality traits (such as strong assertiveness in cluster B personalities) may contribute to achiving leading positions.

The low mean score of the Mini-ICF-APP is only on the first view contraintuitive, when keeping in mind that the reference frame for the judgment of capacity limitations was rather soft, i.e. the general life and general labor market, which means moderate and not highest capacity demands. Furthermore, sick leave does not always come along with high overall limitations, but 
it may be that a limitation in one capacity dimension is important enough to cause sick leave (such as mobility limitation in a field service employee), even if all other capacities are not impaired.

\section{Limitations and strengths}

Limitations of this analysis include the fact that physical health problems and physical capacity limitations have not been addressed. The analysis is part of a wider project and the course and degree of both mental and physical illness load is published in another paper (reference blinded for review). However, this present analysis focuses on mental health-related capacity limitations and thus includes the relevant variables.

Furthermore, participants cannot be clearly classified as suffering from one specific mental health problem (e.g. generalized anxiety) only. This is due to the nature of mental health assessment, i.e. that mental health problems are described in comorbidities at the syndrome level. However, this is a general problem in classificatory research diagnostics [38] and not a specific problem with this study.

Participants were typical patients with chronic mental disorders, and thus generalizability is given, but limited to this group of patients.

It may be the case that the professional groups are not completely homogenous in themselves, due to the multivariate determinedness of the capacity demand profiles of realistic workplaces. Also, capacities may be of relevance in different professions, but in a different way. For example, "teamwork capacity" may be relevant in all professions (e.g. also in office work, due to necessity of work task transfer to colleagues), but may differ in quality and amount. For example, in education professions, teamwork may include being a team leader, and being in front 
of a class or group all the day, whereas in health care there may be stronger need for cooperation and precise information transfer between colleagues, which is another facet of teamwork.

There may be errors in retrospectively reproducing the exact number of weeks of sick leave, e.g. five or six weeks. However, the variance in sick leave duration is high, and it holds relevance whether a person has been on sick leave for about 20 weeks or about 6 weeks. Furthermore, patients are also asked for their sick leave duration by other institutions, and sick leave durations are documented by certificates. Accordingly, the question is not unusual for the patients and validity can be expected.

One strength of this study is that participants were investigated in face-to-face contact in a thorough work-directed medical assessment including observer rating by a study physician with year-long training in the social-medicine assessment of capacity limitations. He was also supervised by a senior socio-medical specialist on a weekly basis. The capacity limitations ratings can thus be expected to be of high ecological validity for this group of persons at risk of work disabilities.

Sick leave duration was differently distributed in the professional groups. This finding might also be influenced by other factors like compensation for sick leave or incentives for remaining in work. Also personality, individual coping strategies, identification with the job and personal ambitions might trigger remaining at work. These factors might be unrelated to objective demands of a specific job. Due to the naturalistic setting, these factors cannot be controlled. Due to the heterogeneous mixture of potential confounders, it is therefore difficult to draw final conclusions. But, even if these factors may all play a role, it is nevertheless interesting that there are observable differences between the groups in sick leave but not in the capacity limitations, which leads to the assumption that context factors (profession-specific work 
demands) are relevant for sick leave.

However, this study with its high ecological validity sheds new light on possible causes for different rates of sick leave in different professions. It may help to better understand why rates of sick leave related to mental health problems rise although the rate of mental disorders in the population remains unchanged [39].

\section{Conclusion and practical aspects}

Observer-rated capacity limitations (Mini-ICF-APP) offer a different level of diagnostic compared with global work ability limitations self-rating (here: IMET) or global sick leave measures. There were no significant differences in capacity limitations degrees between professional groups, whereby the variance was partly explained by psychopathology rather than the professional group. However, the different capacity limitations had different correlation patterns with sick leave. Thus, in social-medicine practice (e.g. decisions on work ability), psychopathology (diagnosis) and capacity limitations must both be considered concerning their contribution to work ability [10].

Even if the capacity limitations of the patients with CMDs investigated here seem to be mild in their degree, this does not mean that they do not hold relevance [e.g. 40]. Whether a capacity limitation (e.g. moderate limitation in contacts with others) becomes a problem or not depends on whether the capacity is strongly demanded (e.g. in service) or not (e.g. in office). This idea is close to the relational idea of the ICF [41], namely that someone $i s$ not impaired, but becomes impaired by the context. 
Funding: This research has been funded by a research grant from the [agency blinded for review]

Conflicts of interest: The author declares that she has no conflicts of interest.

Acknowledgment: The manuscript underwent English language proofreading by Kelly GmbH.

Informed consent and ethical standard: Patients participated in this study with written informed consent. All procedures performed in this study involving human participants were in accordance with the ethical standards of the institutional and/or national research committee and with the 1964 Helsinki Declaration and its later amendments or comparable ethical standards. The study was reviewed and approved by the ethics and data protection committee of the [agency blinded for review].

Data availablility: Data are available from the author. 


\section{References}

1. Wittchen HU, Jacobi F, Rehm J, Gustavsson A, Svensson M, Jönsson B, et al. The size and burden of mental disorders and other disorders of the brain in Europe 2010. Eur Neuropsychopharmacology. 2011;21:655-679. doi: 10.1016/j.euroneuro.2011.07.018

2. Larsen A, Boggild H, Mortensen JT, Foldager L, Hansen J, Christensen A, et al. Mental Health in the Workforce: An Occupational Psychiatry Study. Int J Soc Psychiatry. 2010;56:578-592. doi: $10.1177 / 0020764009345059$

3. Stansfeld SA, Pike C, McManus S, Harris J, Bebbington P, Brugha T, et al. Occupations, work characteristics and common mental disorder. Psychol Med. 2013;43:961-973. doi: $10.1017 / \mathrm{S} 0033291712001821$

4. Wieclaw J, Agerbo E, Mortensen PB, Bonde JP. Occupational risk of affective and stress-related disorders in the Danish workforce. Scand J Work Environ Health. 2005;31:343-351.

5. Gatchel RJ, Polatin PB, Mayer TG, Garcy PD. Psychopathology and the rehabilitation of patients with chronic low back pain disability. Arch Phys Med Rehabil.1994;75:666-670.

6. Cornelius LR, van der Klinik JJL, Groothoff JW, Brouwer S. Prognostic Factors of Long Term Disability due to Mental Disorders: A Systematic Review. J Occup Rehabil.2011;21:259-274.

7. Solli HM, Barbosa da Silva A, Egeland J. Usefulness of an ability-based health model in work ability assessment provided by psychiatrists and psychology specialists writing social security certificates. Disabil Rehabil. 2015;37:571-578. doi: 10.3109/09638288.2014.935491.

8. French JRP Jr. Person role fit. Occup Ment Health. 1973;3:15-20.

9. Edwards JR, van Harrison R. Job demands and worker health: Three-dimensional reexamination of the relationship between person-environment fit and strain. J Appl Psychol. 1993;78:628-648. 
10. WHO. International Classification of Functioning, Disability and Health (ICF). Geneva: World Health Organization; 2001.

11. DRV. Leitlinien für die sozialmedizinische Begutachtung. Sozialmedizinische Beurteilung bei psychischen und Verhaltensstörungen. Berlin: Deutsche Rentenversicherung Bund; 2012.

12. SGPP. Qualitätsleitlinien für psychiatrische Gutachten in der Eidgenössischen Invalidenversicherung. Bern: Schweizerische Gesellschaft für Psychiatrie und Psychotherapie und Schweizerische Gesellschaft für Versicherungspsychiatrie; 2012.

13. Vornholt K, Villotti P, Corbière M, Muschalla B, Nijhuis FJN, Zijlstra FRH, Colella A. Disability and Employment. State of the Art and Future Outlook. Eur J Work Organizational Psychol. 2018;27: 40-55. doi: 10.1080/1359432X.2017.1387536

14. Linden M, Baron S, Muschalla B. Mini-ICF-Rating für psychische Störungen (Mini-ICF-APP). Ein Kurzinstrument zur Beurteilung von Fähigkeits- bzw. Kapazitätsstörungen bei psychischen Störungen. [A short rating for capacity limitations in mental disorders (Mini-ICF-APP)]. Göttingen: Hans Huber; 2009, 2015.

15. Balestrieri M, Isola M, Bonn R, Tam T, Vio A, Linden M, Maso E. Validation of the Italian version of Mini-ICF-APP, a short instrument for rating activity and participation restrictions in psychiatric disorders. Epidemiol Psychiatr. Sci. 2012;22:81-91. doi: 10.1017/S2045796012000480

16. Molodynski A, Linden M, Juckel G, Yeeles K, Anderson C, Vazquez-Montes M, et al. The reliability, validity, and applicability of an English language version of the Mini-ICF-APP. Soc Psychiatry Psychiatr Epidemiol. 2013;48:1347-1354. doi: 10.1007/s00127-012-0604-8

17. Muschalla B. Different work capacity impairments in patients with different work-anxieties. Int Arch Occup Environ Health. 2016;89:609-619. 
18. Stansfeld SA, Clark C, Caldwell T, Rodgers B, Power C. Psychosocial work characteristics and anxiety and depressive disorders in midlife: the effects of prior psychological distress. Occup Environ Med. 2008;65:634-642. doi: 10.1136/oem.2007.036640

19. Pinna F, Fiorillo A, Tusconi M, Guiso B, Carpiniello B. Assessment of functioning in patients with schizophrenia and schizoaffective disorders with the Mini-ICF-APP: a validation study in Italy. Int J Ment Health Systems. 2015;9:37. doi: 10.1186/s13033-015-0030-x.

20. Muschalla B, Vilain M, Lawall C, Lewerenz M, Linden M. Participation restrictions at work indicate participation restrictions in other domains of live. Psychol Health Med. 2012;17:95-104.

21. de Vries H, Fishta A, Weikert B, Rodriguez Sanchez A, Wegewitz U. Determinants of Sickness Absence and return To Work Among Employees with Common mental Disorders: A Scoping Review. J Occup Rehabil. 2018;28:393-417. doi: 10.1007/s10926-017-9730-1.

22. Victor M, Lau B, Ruud T. Predictors of return to Work 6 Moneths After the End of treatment in Paients with Common Mental Disorders: A Cohort Study. J Occup Rehabil. 2018;28:548-558. doi: $10.1007 / \mathrm{s} 10926-017-9747-5$.

23. Muschalla B. Fähigkeitsorientierte Verhaltenstherapie bei psychischen Erkrankungen. [Capacityoriented behavior therapy in mental disorders]. Verhaltenstherapie. 2014;24:48-55.

24. WHO. WHO Fünf. Fragebogen zum Wohlbefinden. WHO Collaborating Center for Mental Health, Psychiatric Research Unit, Frederiksborg General Hospital, Denmark; 1998.

25. Deck R, Walther AL, Staupendahl A, Katalinic A. Limitations of social participation in general population - normative data of the IMET based on a population-based survey in northern Germany. Rehabilitation. 2015;54:402-408. doi: 10.1055/s-0035-1559670. 
26. Linden M, Muschalla B, Noack N, Heintze C, Döpfmer S. Treatment Changes in General Practice Patients with Chronic Mental Disorders following a Psychiatric-Psychosomatic Consultation. Health Services Research and Managerial Epidemiology. 2018;5:1-6. doi: 10.1177/2333392818758523.

27. Sheehan D, Lecrubier Y, Sheehan H, Amorim P, Janavs J, Weiller E, et al. The Mini International Neuropsychiatric Interview: the development and validation of a structured diagnostic psychiatric interview for DSM-IV and ICD-10. J Clin Psychiatry. 1998;59:22-33.

28. Wiersma D, DeJong A, Kraaijkamp HJM, Ormel J. The Groningen Social Disability Schedule. Manual and Questionnaires. Second Version. University of Groningen, Department of Social Psychiatry; 1990.

29. Muschalla B, Linden M. Workplace Phobia - A first explorative study on its relation to established anxiety disorders, sick leave, and work-directed treatment. Psychol Health Med. 2009;14:591-605. doi: 10.1080/13548500903207398.

30. Ekberg K, Wahlin C, Persson J, Bernfort L, Oberg B. Early and late return to work after sick leave: predictors in a cohort of sick-listed individuals with common mental disorders. J Occup Rehabil. 2015;25:627-637.

31. Netterstrom B, Eller NH, Borritz M. Prognostic factors of returning to work after sick leave due to work-related common mental disorders: a one- and three-year follow-up study. Biomed Res Int. 2015:596572.

32. Sampere M, Gimeno D, Serra C, Plana M, Lopez JC, Martinez JM, et al. Return to work expectations of workers on long-term non-work-related sick leave. J Occup Rehabil. 2012;22:15-26.

33. Lidwall U, Bill S, Palmer E, Olsson Bohlin C. Mental disorders sick leave in Sweden: A population study. Work. 2018, ahead of print. doi: 10.3233/WOR-172672

34. Shearer S, Gordon L. The patient with excessive worry. Am Fam Physician. 2006;15:1049-1056. 
35. Sanne B, Mykletun A, Dahl AA, Moen BE, Tell GS. Occupational differences in levels of anxiety and depression: the Hordaland Health Study. J Occup Environ Med. 2003;45:628-638.

36. Kaila-Kangas, L., Koskinen, A., Pensola, T., Mäkelä, P., Leino-Arjas P. Alcohol-induced morbidity and mortality by occupation: a population-based follow-up study of working Finns. Eur J Public Health. 2016;26:116-122. doi: 10.1093/eurpub/ckv145.

37. Gotzsche-Astrup O, Jakobsen J, Furnham A. The higher you climb: Dark side personality and job level. Scand J Psychol. 2016;57:535-541. doi: 10.1111/sjop.12305.

38. Linden M, Muschalla B. Standardized diagnostic interviews, criteria, and algorithms for mental disorders: garbage in, garbage out. Eur Arch Psychiatr Clini Neurosci. 2012;262:535-544.

39. Jacobi F, Linden M. Macht die moderne Arbeitswelt psychisch krank - oder kommen psychisch Kranke in der modernen Arbeitswelt nicht mehr mit? Arbeitsmed Sozialmed Umweltmed. 2018;53:530-536.

40. Tuithof M, TenHave M, Beekman A, van Dorsselaer S, Kleinjan M, Schaufeli W, \& de Graaf R. The interplay between emotional exhaustion, common mental disorders, functioning and health care use in the working population. J Psychosom Res. 2017; 100:8-14. doi:

10.1016/j.jpsychores.2017.06.018

41. Mitra S, Shakespeare T. Remodeling the ICF. Disability Health J. 2019; in press.

42. Field A. Discovering Statistics using IBM SPSS Statistics. Sage Publications Ltd., London, 2013. 
Table 1. Illness-related characteristics of persons with chronic mental disorders from different profession groups (percentages for frequencies; means (standard deviation) for age).

Contingency coefficient for nominal scaled variables (Gender, disorders), or ANOVA (age) have been calculated.

\begin{tabular}{|c|c|c|c|c|c|c|c|c|}
\hline & $\begin{array}{c}1 \\
\text { Physical } \\
\text { work / } \\
\text { craftsmen } \\
(\mathrm{n}=37)\end{array}$ & $\begin{array}{c}2 \\
\text { Health } \\
\text { services } \\
(\mathrm{n}=43)\end{array}$ & $\begin{array}{c}3 \\
\text { Education } \\
(\mathrm{n}=29)\end{array}$ & $\begin{array}{c}4 \\
\text { Office } \\
\text { work } \\
(n=72)\end{array}$ & $\begin{array}{c}5 \\
\text { Services, } \\
\text { mobility } \\
(\mathrm{n}=40)\end{array}$ & $\begin{array}{c}6 \\
\text { Manager, } \\
\text { Academics, } \\
\text { leading } \\
\text { position } \\
(\mathrm{n}=38)\end{array}$ & $\begin{array}{c}\text { All } \\
(\mathrm{N}=263)\end{array}$ & $\begin{array}{l}\text { Significance } \\
\text { of } \\
\text { difference } \\
\text { between the } \\
\text { groups } \\
p\end{array}$ \\
\hline Gender male & $62.2 \%$ & $11.6 \%$ & $6.9 \%$ & $13.9 \%$ & $36.4 \%$ & $52.6 \%$ & $28.9 \%$ & $<.01$ \\
\hline Age & $\begin{array}{l}44.95 \\
(8.83)\end{array}$ & $\begin{array}{c}42.65 \\
(11.16)\end{array}$ & $\begin{array}{l}49.90 \\
(7.98)\end{array}$ & $\begin{array}{l}43.38 \\
(9.90)\end{array}$ & $\begin{array}{c}43.43 \\
(10.39)\end{array}$ & $\begin{array}{l}42.87 \\
(9.60)\end{array}$ & $\begin{array}{l}44.13 \\
(9.97)\end{array}$ & $\begin{array}{l}\text { overall test: } \\
.03 \\
\text { Pairwise } \\
\text { comparisons: } \\
{ }^{2 v s 3} .04 \\
{ }^{3 v s 4} .04\end{array}$ \\
\hline
\end{tabular}

Disorder(s)

according to

MINI

\begin{tabular}{|c|c|c|c|c|c|c|c|c|}
\hline Depression & $64.9 \%$ & $48.8 \%$ & $27.6 \%$ & $43.1 \%$ & $40.9 \%$ & $42.1 \%$ & $44.9 \%$ & .07 \\
\hline Agoraphobia & $27.0 \%$ & $30.2 \%$ & $13.8 \%$ & $26.4 \%$ & $27.3 \%$ & $13.2 \%$ & $23.9 \%$ & .34 \\
\hline $\begin{array}{l}\text { Social } \\
\text { Phobia }\end{array}$ & $5.4 \%$ & $18.6 \%$ & $0.0 \%$ & $6.9 \%$ & $9.1 \%$ & $7.9 \%$ & $8.4 \%$ & .10 \\
\hline $\begin{array}{l}\text { Generalised } \\
\text { Anxiety }\end{array}$ & $5.4 \%$ & $9.3 \%$ & $3.4 \%$ & $19.4 \%$ & $4.5 \%$ & $7.9 \%$ & $9.9 \%$ & .05 \\
\hline $\begin{array}{l}\text { Alcohol } \\
\text { addiction }\end{array}$ & $13.5 \%$ & $4.7 \%$ & $3.4 \%$ & $4.2 \%$ & $6.8 \%$ & $5.3 \%$ & $6.1 \%$ & .21 \\
\hline $\begin{array}{l}\text { Adjustment } \\
\text { Disorder }\end{array}$ & $16.2 \%$ & $20.9 \%$ & $6.9 \%$ & $11.1 \%$ & $15.9 \%$ & $10.5 \%$ & $13.7 \%$ & .53 \\
\hline $\begin{array}{l}\text { Personality } \\
\text { Disorder }\end{array}$ & $8.1 \%$ & $6.9 \%$ & $6.9 \%$ & $6.9 \%$ & $6.8 \%$ & $0.0 \%$ & $6.1 \%$ & .71 \\
\hline $\begin{array}{l}\text { Workplace } \\
\text { Phobia }\end{array}$ & $8.1 \%$ & $17.5 \%$ & $13.8 \%$ & $13.6 \%$ & $5.1 \%$ & $2.7 \%$ & $10.5 \%$ & .23 \\
\hline
\end{tabular}

Note: An analysis of variance (ANOVA [42]) has been conducted for the variable age. Overall test signals that there are any age differencs between the professional groups. Pairwise comparisons compare the professional groups directly.

Due to the methodological artifact of possible comorbidities in standardized interviews like the MINI, percentages of disorders per professional group can add up to $>100 \%$. There can be 
accompanying disorders with shorter duration ( $<6$ months, e.g. adjustment disorder) in case the main disorder is of longer duration and therefore fulfills the chronicity criterion (e.g. recurrent depressive episodes for ten years, or generalized anxiety disorder). 
Table 2. Sick leave and subjective work ability limitations (IMET) of persons with mental disorders from different professions. Means (standard deviation).

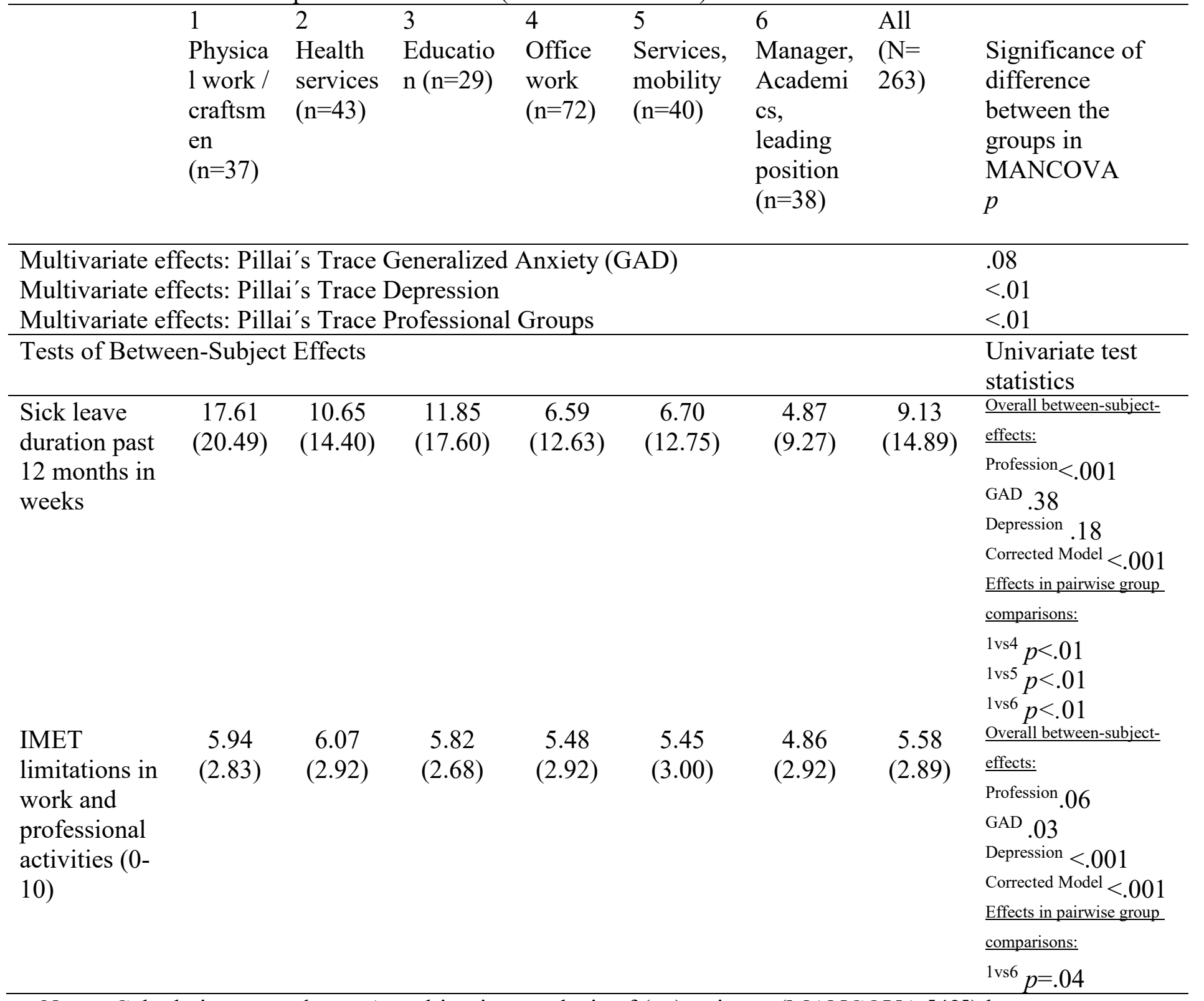

Notes: Calculation procedures: A multivariate analysis of (co)variance (MANCOVA [42]) has been conducted. Multivariate test's (Pillai's Trace) signal which variables (GAD, depression, professional group) explain the overall variance of IMET and sick leave duration. Separate univariate analysis (Between-Subject Effects) refer to one single variable (e.g. sick leave duration) and signal which variables explain it's variance. Corrected model signals whether the overall analysis is significant; significance levels of the covariates profession, GAD, depression are shown. Additional pairwise comparisons compare the professional groups directly. Thereby, bonferroni correction has been used to control for Type 1 error.

Reading help for the values displayed in the table: According to Pillai's Trace, overall differences in IMET and sick leave duration are explained significantly by professional group $(p<.01)$, and the diagnosis $\operatorname{GAD}(p=.08)$ and depression $(p<.01)$. Additional univariate test 
statistic shows that the overall variation of sick leave duration is rather explained by profession $(p<.001)$ but not by depression $(p=.18)$ or $\operatorname{GAD}(p=.38)$. Additional significant effects in pairwise group comparisons are also shown in the right column. Sick leave duration in physical workers is significantly longer than in office workers, service workers, managers (1vs4, 1vs5, 1 vs6 are all $p<01)$. 
Table 3. Capacity limitations (Mini-ICF-APP) of persons with mental disorders from different professions. Means (Standard deviation).

\begin{tabular}{|c|c|c|c|c|c|c|c|c|}
\hline & $\begin{array}{l}1 \\
\text { Physical } \\
\text { work / } \\
\text { craftsmen } \\
(\mathrm{n}=37)\end{array}$ & $\begin{array}{l}2 \\
\text { Health } \\
\text { services } \\
(n=43)\end{array}$ & $\begin{array}{l}3 \\
\text { Education } \\
(\mathrm{n}=29)\end{array}$ & $\begin{array}{l}4 \\
\text { Office } \\
\text { work } \\
(n=72)\end{array}$ & $\begin{array}{l}5 \\
\text { Services, } \\
\text { mobility } \\
(\mathrm{n}=40)\end{array}$ & $\begin{array}{l}6 \\
\text { Manager } \\
\text { Academ } \\
\text { ics, } \\
\text { leading } \\
\text { position } \\
(\mathrm{n}=38)\end{array}$ & $\begin{array}{l}\text { All } \\
(N= \\
263)\end{array}$ & $\begin{array}{l}\text { Significance of } \\
\text { difference } \\
\text { between the } \\
\text { groups in } \\
\text { MANCOVA } \\
p\end{array}$ \\
\hline \multicolumn{8}{|c|}{$\begin{array}{l}\text { Multivariate test: Pillai's Trace Depression } \\
\text { Multivariate tests: Pillai's Trace Professional Groups }\end{array}$} & $\begin{array}{l}.08 \\
<.001 \\
.06\end{array}$ \\
\hline \multicolumn{8}{|c|}{ Tests of Between-Subject Effects } & $\begin{array}{l}\text { Univariate test } \\
\text { statistics }\end{array}$ \\
\hline $\begin{array}{l}\text { Adherence to } \\
\text { regulations }\end{array}$ & $\begin{array}{c}0.62 \\
(0.95)\end{array}$ & $\begin{array}{c}0.35 \\
(0.65)\end{array}$ & $\begin{array}{c}0.84 \\
(0.74)\end{array}$ & $\begin{array}{c}0.39 \\
(0.70)\end{array}$ & $\begin{array}{c}0.52 \\
(0.79)\end{array}$ & $\begin{array}{c}0.34 \\
(0.63)\end{array}$ & $\begin{array}{c}0.44 \\
(0.74)\end{array}$ & $\begin{array}{l}\text { Profession } .59 \\
\text { GAD } .69 \\
\text { Depression }<.01 \\
\text { Corrected Model } .02\end{array}$ \\
\hline $\begin{array}{l}\text { Planning and } \\
\text { structuring } \\
\text { tasks }\end{array}$ & $\begin{array}{c}0.92 \\
(1.01)\end{array}$ & $\begin{array}{c}0.58 \\
(0.82)\end{array}$ & $\begin{array}{c}0.66 \\
(0.66)\end{array}$ & $\begin{array}{c}0.57 \\
(0.77)\end{array}$ & $\begin{array}{c}0.64 \\
(0.84)\end{array}$ & $\begin{array}{c}0.66 \\
(0.75)\end{array}$ & $\begin{array}{c}0.65 \\
(0.81)\end{array}$ & $\begin{array}{l}\text { Profession } .56 \\
\text { GAD } .21 \\
\text { Depression }<.001 \\
\text { Corrected Model }<.001\end{array}$ \\
\hline Flexibility & $\begin{array}{c}0.89 \\
(1.05)\end{array}$ & $\begin{array}{c}0.91 \\
(0.95)\end{array}$ & $\begin{array}{c}0.69 \\
(0.85)\end{array}$ & $\begin{array}{c}1.21 \\
(0.98)\end{array}$ & $\begin{array}{c}1.07 \\
(1.07)\end{array}$ & $\begin{array}{c}0.84 \\
(0.92)\end{array}$ & $\begin{array}{c}0.98 \\
(0.98)\end{array}$ & $\begin{array}{l}\text { Profession } .21 \\
\text { GAD } .07 \\
\text { Depression }<.001 \\
\text { Corrected Model }<.001\end{array}$ \\
\hline $\begin{array}{l}\text { Capacity to } \\
\text { judge and } \\
\text { decide }\end{array}$ & $\begin{array}{c}0.97 \\
(1.16)\end{array}$ & $\begin{array}{l}1.00 \\
(0.89)\end{array}$ & $\begin{array}{c}0.55 \\
(0.74)\end{array}$ & $\begin{array}{c}1.17 \\
(0.90)\end{array}$ & $\begin{array}{c}0.89 \\
(0.92)\end{array}$ & $\begin{array}{c}0.76 \\
(0.85)\end{array}$ & $\begin{array}{c}0.94 \\
(0.93)\end{array}$ & $\begin{array}{l}\text { Profession } .22 \text { GAD } \\
<.01 \\
\text { Depression }<.001 \\
\text { Corrected Model }<.001\end{array}$ \\
\hline Endurance & $\begin{array}{l}1.16 \\
(1.07)\end{array}$ & $\begin{array}{l}1.00 \\
(1.02)\end{array}$ & $\begin{array}{c}0.76 \\
(0.83)\end{array}$ & $\begin{array}{c}1.17 \\
(1.10)\end{array}$ & $\begin{array}{c}0.86 \\
(1.05)\end{array}$ & $\begin{array}{c}0.82 \\
(0.86)\end{array}$ & $\begin{array}{c}0.99 \\
(1.02)\end{array}$ & $\begin{array}{l}\text { Profession } .62 \\
\text { GAD } .08 \\
\text { Depression }<.001 \\
\text { Corrected Model }<.001\end{array}$ \\
\hline $\begin{array}{l}\text { Contacts } \\
\text { with others }\end{array}$ & $\begin{array}{c}0.84 \\
(0.96)\end{array}$ & $\begin{array}{c}0.79 \\
(0.91)\end{array}$ & $\begin{array}{c}0.38 \\
(0.62)\end{array}$ & $\begin{array}{c}0.88 \\
(0.91)\end{array}$ & $\begin{array}{c}0.75 \\
(0.84)\end{array}$ & $\begin{array}{c}0.50 \\
(0.65)\end{array}$ & $\begin{array}{c}0.73 \\
(0.86)\end{array}$ & $\begin{array}{l}\text { Profession } .15 \\
\text { GAD } .16 \\
\text { Depression }<.01 \\
\text { Corrected Model }<.01\end{array}$ \\
\hline $\begin{array}{l}\text { Teamwork } \\
\text { capacity }\end{array}$ & $\begin{array}{c}0.65 \\
(0.89)\end{array}$ & $\begin{array}{c}0.63 \\
(0.87)\end{array}$ & $\begin{array}{c}0.21 \\
(0.49)\end{array}$ & $\begin{array}{c}0.65 \\
(0.89)\end{array}$ & $\begin{array}{c}0.73 \\
(0.92)\end{array}$ & $\begin{array}{c}0.50 \\
(0.73)\end{array}$ & $\begin{array}{c}0.59 \\
(0.84)\end{array}$ & $\begin{array}{l}\text { Profession } .24 \\
\text { GAD } .76 \\
\text { Depression }<.01 \\
\text { Corrected Model } .02\end{array}$ \\
\hline Assertiveness & $\begin{array}{c}0.86 \\
(0.94)\end{array}$ & $\begin{array}{c}0.98 \\
(0.77)\end{array}$ & $\begin{array}{c}0.45 \\
(0.78)\end{array}$ & $\begin{array}{c}0.97 \\
(0.95)\end{array}$ & $\begin{array}{c}0.84 \\
(0.94)\end{array}$ & $\begin{array}{c}0.53 \\
(0.73)\end{array}$ & $\begin{array}{c}0.81 \\
(0.89)\end{array}$ & $\begin{array}{l}\text { Profession } .04 \\
\text { GAD .84 } \\
\text { Depression }<.001\end{array}$ \\
\hline
\end{tabular}




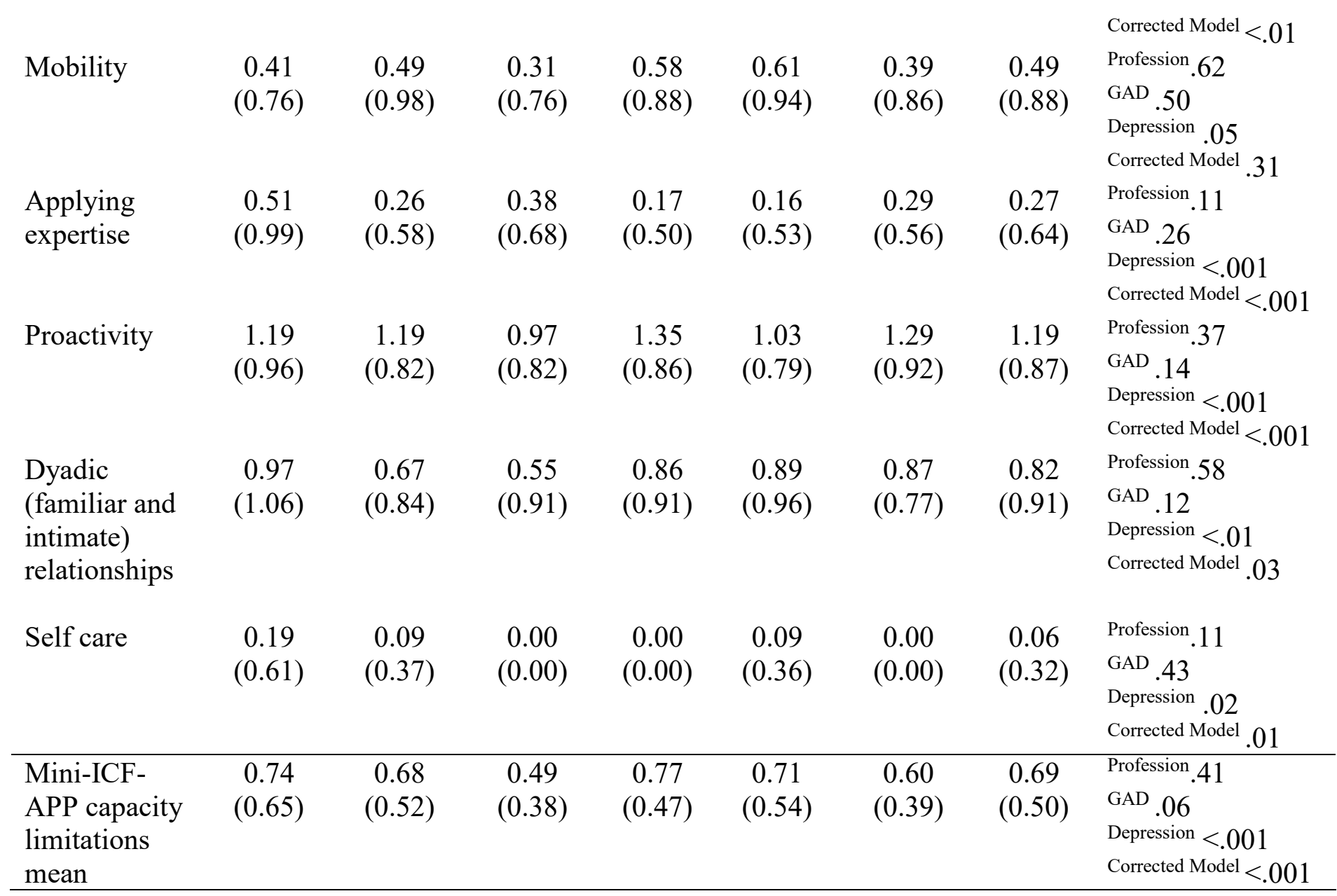

Notes: Calculation procedures: A multivariate analysis of (co)variance (MANCOVA [42]) has been conducted. Multivariate test's (Pillai's Trace) signal which variables (GAD, depression, professional group) explain the overall variance of the here investigated capacity limitations. Separate univariate analysis (Between-Subject Effects) refer to specific capacity limitations (e.g. adherence to regulations) and signal which variables explain it's variance. Corrected model signals whether the overall analysis is significant; significance levels of the covariates profession, GAD, depression are shown. Additional pairwise comparisons compare the professional groups directly. Thereby, bonferroni correction has been used to control for Type 1 error.

Reading help for the values displayed in the table: According to Pillai's Trace, overall variance of capacity limitations is explained significantly by professional group $(p=.06)$, and the diagnosis $\operatorname{GAD}(p=.08)$ and depression $(p<.001)$. Additional univariate test statistics show that variance in limitations of adherence to regulations are rather explained by depression $(p<.01)$ but not by profession $(p=.59)$.

There were no additional significant effects in pairwise group comparisons for any of the capacity limitations. Therefore effects are not displayed in the table. 
Table 4. Correlations of capacity limitations with sick leave duration in different professional groups.

\begin{tabular}{|c|c|c|c|c|c|c|c|}
\hline & $\begin{array}{l}1 \\
\text { Physical } \\
\text { work / } \\
\text { craftsmen } \\
(\mathrm{n}=37)\end{array}$ & $\begin{array}{l}2 \\
\text { Health } \\
\text { services } \\
(n=43)\end{array}$ & $\begin{array}{l}3 \\
\text { Education } \\
(\mathrm{n}=29)\end{array}$ & $\begin{array}{l}4 \\
\text { Office } \\
\text { work } \\
(n=72)\end{array}$ & $\begin{array}{l}5 \\
\text { Services, } \\
\text { mobility } \\
(n=40)\end{array}$ & $\begin{array}{l}6 \\
\text { Manager, } \\
\text { Academic } \\
\mathrm{s} \text {, leading } \\
\text { position } \\
(\mathrm{n}=38)\end{array}$ & $\begin{array}{l}\text { All } \\
(N=263)\end{array}$ \\
\hline $\begin{array}{l}\text { Adherence to } \\
\text { regulations }\end{array}$ & .14 & -.02 & -.07 & .14 & -.06 & -.05 & .07 \\
\hline $\begin{array}{l}\text { Planning and } \\
\text { structuring tasks }\end{array}$ & .18 & .04 & -.04 & -.01 & -.09 & .04 & .07 \\
\hline Flexibility & .39 & $.35^{*}$ & .42 & .09 & .28 & -.05 & $.22 * *$ \\
\hline $\begin{array}{l}\text { Capacity to } \\
\text { judge and decide }\end{array}$ & $.45^{* *}$ & .29 & $.54 * *$ & .12 & .07 & .18 & $.24 * *$ \\
\hline Endurance & $.45^{* *}$ & $.50^{* *}$ & $.40^{*}$ & .21 & .19 & .12 & $.30^{* *}$ \\
\hline $\begin{array}{l}\text { Contacts with } \\
\text { others }\end{array}$ & $.38^{*}$ & -.02 & -.16 & .06 & $.39 *$ & -.22 & $.14^{*}$ \\
\hline $\begin{array}{l}\text { Teamwork } \\
\text { capacity }\end{array}$ & $.38^{*}$ & -.10 & $<.01$ & -.02 & $.41 * *$ & -.20 & $.13^{*}$ \\
\hline Assertiveness & .22 & -.08 & .26 & -.10 & .13 & .17 & .08 \\
\hline Mobility & .21 & .10 & .06 & .04 & .13 & -.01 & .06 \\
\hline $\begin{array}{l}\text { Applying } \\
\text { expertise }\end{array}$ & .25 & $.40^{* *}$ & .39 & $<.01$ & .25 & -.24 & $.24 * *$ \\
\hline Proactivity & .26 & .12 & -.09 & .14 & .05 & .25 & .07 \\
\hline $\begin{array}{l}\text { Dyadic (familiar } \\
\text { and intimate) } \\
\text { relationships }\end{array}$ & .34 & -.10 & $<.01$ & $<.01$ & .24 & $.48^{* *}$ & $.13^{*}$ \\
\hline Self care & $.38^{*}$ & .29 & - & - & -.05 & - & $.17^{*}$ \\
\hline $\begin{array}{l}\text { Mini-ICF-APP } \\
\text { capacity } \\
\text { limitations mean }\end{array}$ & $.48^{* *}$ & .25 & .30 & .10 & .26 & .11 & $.26^{* *}$ \\
\hline $\begin{array}{l}\text { IMET } \\
\text { limitations in } \\
\text { work and } \\
\text { professional } \\
\text { activities }\end{array}$ & $.69^{* *}$ & .21 & $.50^{* *}$ & .06 & $.43^{* *}$ & .13 & $.33^{* *}$ \\
\hline
\end{tabular}

Notes: Partial correlations have been calculated: Capacity limitations are correlated with sick leave duration in the past 12 months, with generalized anxiety and depression as control variables. Correlations' level of significance is $*_{p}<.05$, or $*^{*} p<.01$. 